\title{
Acoustic Investigations of Ga-Pb Miscibility Gap Melts
}

\author{
V. V. Filippov \\ Ural Federal University, ul. Mira 19, Yekaterinburg, 620002 Russia \\ e-mail:vvfilippov@mail.ru \\ Received November 8, 2012
}

\begin{abstract}
The ultrasound velocity is measured in $\mathrm{Ga}-\mathrm{Pb}$ melts from the monotectic temperature to $1100 \mathrm{~K}$ over the entire concentration range by a pulsed-phase method. Anomalies are detected in the temperature dependences of the ultrasound velocity near the critical point. The boundary of the miscibility gap is determined from the results of acoustic measurements. The miscibility gap temperatures measured by the acoustic method agree well with the reported data.
\end{abstract}

DOI: $10.1134 / \mathrm{S} 003602951302016 \mathrm{X}$

\section{INTRODUCTION}

The signs of microsegregation of atoms of the same kind were detected in miscibility gap systems in the field of the single-phase state of melts. The X-ray diffraction patterns of such melts can be represented as the superposition of the X-ray diffraction patterns of the pure components [1]. Various anomalies (in particular, viscosity and electrical resistivity maxima [2]) are visible in property isotherms at temperatures insignificantly higher than the critical miscibility gap temperature near the critical concentration. The appearance of microsegregation in such systems is related to a preferred interaction of atoms of the same kind and can occur near the critical point by a fluctuation way. However, the fluctuation scale should decrease rapidly with the distance from the critical point.

The purpose of this work is to measure the ultrasound velocity in $\mathrm{Ga}-\mathrm{Pb}$ melts and to determine the miscibility gap boundary for them from these measurements.

\section{EXPERIMENTAL}

Ultrasound velocity $v_{s}$ in $\mathrm{Ga}-\mathrm{Pb}$ melts was measured by a pulsed-phase method. It is based on direct measurements of wavelength $\lambda$ and sound frequency $f$ and the subsequent calculation of the sound velocity by the formula

$$
v_{\mathrm{s}}=\lambda f \text {. }
$$

Figure 1 shows the schematic diagram of the experimental setup. A G5-72 generator emits rectangular 1 - to $5-\mu$ s electric signals at a repetition frequency of $\sim 800 \mathrm{~Hz}$, and they are filled with a high-frequency $(f=33.83 \mathrm{MHz})$ sinusoidal voltage pulses supplied from a G4-151 generator. The pulse amplitude is smoothly controlled in the range $0-10 \mathrm{~V}$. Pulses are supplied to the lower emitting piezoelectric elements of measuring and reference cells, which have the same design and are connected in parallel. The working cell is preliminarily filled with a metallic melt to be studied, and the reference cell is filled with distilled water.

After passing through the measuring and reference cells, acoustic pulses are directed to the upper receiving piezoelectric elements, where they are again converted into electric pulses. Since the delay times of acoustic signals in both cells are chosen to be approximately the same, the electric pulses at their output pass through a connecting circuit and interfere with each other. The result of this interference is enhanced in a selective detector and is visible on an oscilloscope display.

The upper waveguide of the measuring cell can move along its vertical axis, and the displacement is measured by a digital micrometer with a scale interval of $0.001 \mathrm{~mm}$. In this case, a sequence of interference signal extrema, which are spaced sound wavelength $\lambda$ apart, are visible on the oscilloscope display.

Therefore, the sound wavelength in the melt can be calculated by the formula

$$
\lambda=\Delta h / n,
$$

where $n$ is the number of the minima of the resulting oscillation detected on the oscilloscope display when the upper waveguide of the measuring cell travels distance $\Delta h$. Then, with allowance for Eqs. (1) and (2), the sound velocity in the melt under study is

$$
v_{\mathrm{s}}=(\Delta h / n) f \text {. }
$$

This method of acoustic measurements is characterized by the possibility of measuring the local ultrasound velocity at various distances from the crucible bottom, which makes it possible to detect a macroscopic heterogeneity of the melt in height (e.g., the separation of the melt into two liquid phases). The authors of [3, 4] showed that the position of the boundary between two liquids can be determined from both an ultrasound velocity jump and a sharp decrease in the amplitude of 


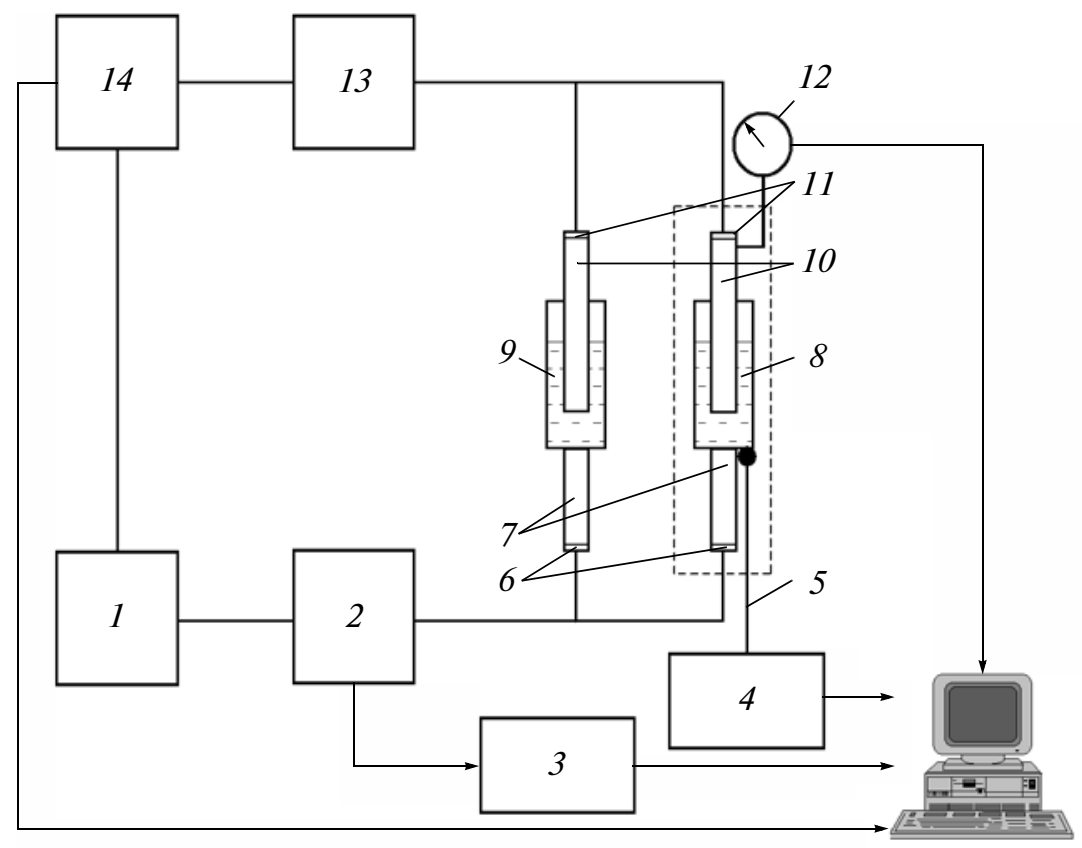

Fig. 1. Schematic diagram of the experimental setup: (1) pulsed-signal generator, (2) sinusoidal signal generator, (3) frequency meter, (4) digital voltmeter, (5) thermocouple, (6) and (11) piezoelectric elements, (7) and (10) waveguides, (8) container with a sample, (9) container with a reference liquid, (12) digital micrometer, (13) selective amplifier, and (14) digital oscilloscope.

an ultrasonic signal passing through a melt. The accuracy of determining this boundary from the ultrasonic signal amplitude is an order of magnitude higher than the accuracy of determining this boundary from the ultrasound velocity [4]. The miscibility gap temperature can be determined from the appearance or disappearance of the boundary between two liquids upon cooling or heating of a sample.

Another method of determining a miscibility gap is based on measuring the ultrasound velocity in oneand two-phase fields. We measured the temperature dependences of the ultrasound velocity in a one-phase field for alloys of various compositions and then constructed their concentration dependences. In a twophase field, we measured temperature-concentration dependence $v_{s}(T, x)$ along a miscibility gap. The points of intersection of measured ultrasound velocity isotherms with curve $v_{s}(T, x)$ determine the coordinates of the miscibility gap for a certain temperature.

The authors of $[5,6]$ proposed a very sensitive and simple method of static loading to find solidus, monotectic, and eutectic points. This method can be executed using the equipment for measuring the ultrasound velocity by the pulsed-phase method. The temperature dependence of the size of the solid part of a sample $h$ (i.e., the distance between the waveguides strongly pressed against this part) was determined in heating at a rate of $0.5-1 \mathrm{~K} / \mathrm{h}$. When a liquid phase appears at a small load applied to the upper waveguide, $h$ decreases sharply and the phase-transition temperature can be detected accurate to $0.5 \mathrm{~K}$. The tempera- ture of the end of sample melting can be determined from the appearance of an acoustic signal [4].

The carrier frequency of acoustic vibrations $(f=$ $33.83 \mathrm{MHz}$ ) was measured by an electronic frequency meter at an absolute error of $\pm 50 \mathrm{~Hz}$, which is about $\pm 2 \times 10^{-4} \%$ in relative units. Therefore, the error of measuring the sound wave length mainly contributes to the error of determining the ultrasound velocity. To increase the experimental accuracy, we have to increase acoustic base $\Delta h$ of these measurements.

The samples were alloyed in a quartz measuring cell from gallium of $99.999 \mathrm{wt} \%$ purity and lead of 99.99 wt \% purity. The ultrasound velocity was measured in a high-purity helium atmosphere upon cooling from $1100 \mathrm{~K}$ to the monotectic temperature. Every experimental point was obtained after isothermal holding of a sample for $30 \mathrm{~min}$ at a temperature maintained accurate to $\pm 0.5 \mathrm{~K}$. The ultrasound velocity corresponding to this temperature was averaged over $10-$ 20 measurements at an acoustic base $\Delta h=3-4 \mathrm{~mm}$. The random error in determining the average value did not exceed $0.3 \%$ at a systematic error of about $0.03 \%$.

\section{RESULTS AND DISCUSSION}

We measured ultrasound velocity $\mathrm{v}_{\mathrm{s}}$ as a function of temperature for pure gallium, lead, and their alloys containing $10,20,30,35,38,40,44,50,60,70,80$, and 90 at $\% \mathrm{Ga}$. 


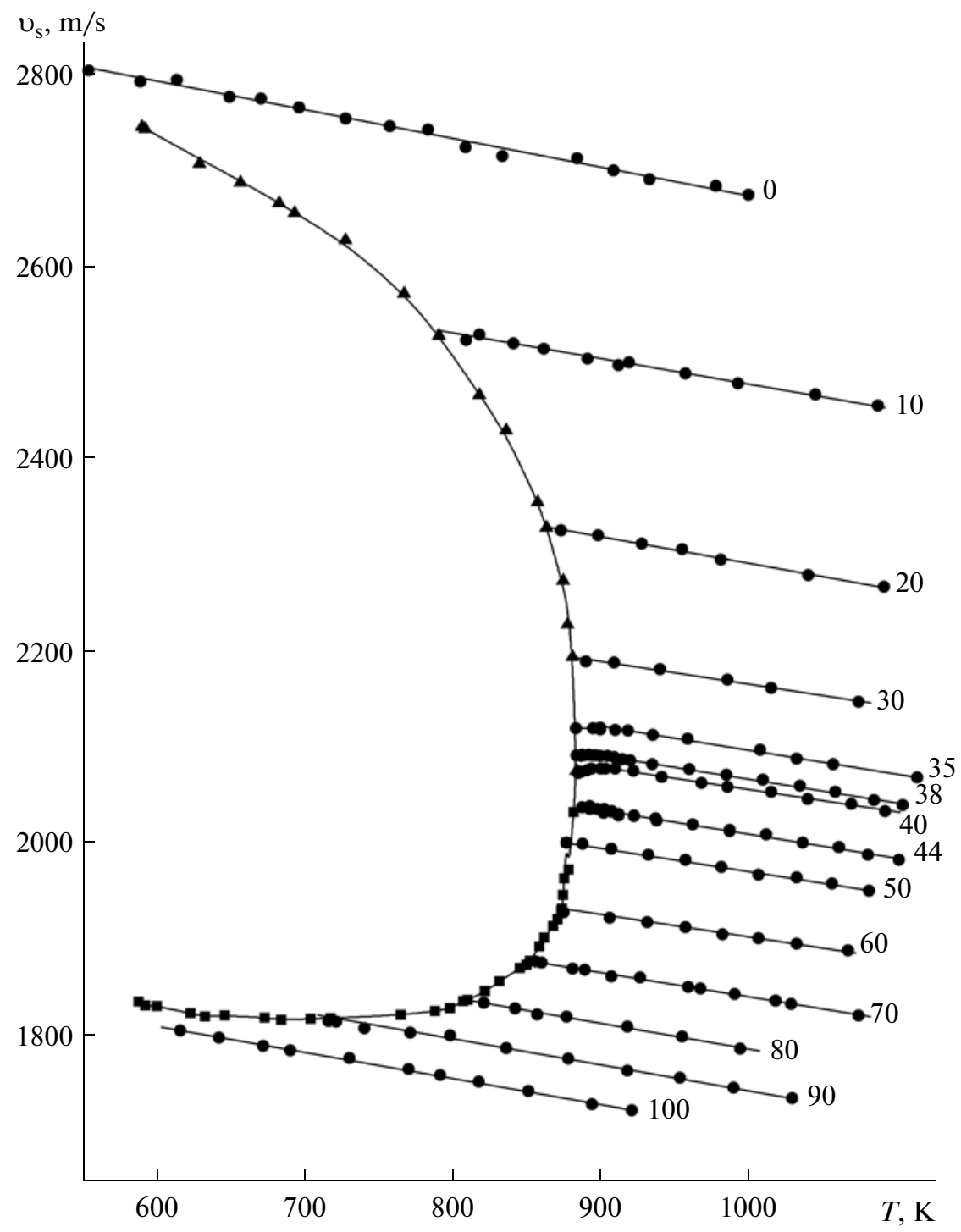

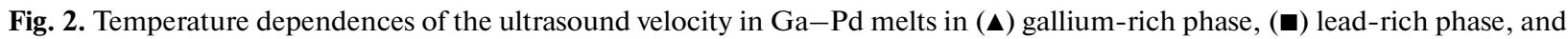
$(\bullet)$ single-phase field. Numerals at the curves, the lead content in an alloy (at \%).

Figure 2 shows the temperature dependences of $v_{s}$ in liquid gallium-lead alloys. The ultrasound velocity increases linearly with decreasing temperature down to miscibility gap $T_{\mathrm{mg}}$ for all compositions under study except for the melts containing 35,38 , and 40 at $\% \mathrm{~Pb}$, where $v_{\mathrm{s}}$ deviates from a linear run below $910 \mathrm{~K}$. This anomaly is related to the preferred interaction of atoms of the same kind near the critical point.

Table 1 gives the coefficients in the equation

$$
\mathrm{v}_{\mathrm{s}}(T)=b_{0}-b_{1} T \text {, }
$$

obtained by the least squares method.

Below $T_{\mathrm{mg}}$, the $v_{\mathrm{s}}(T)$ curve splits into two curves: the lower branch describes the ultrasound velocity in a lead-rich phase $\left(\mathrm{v}_{\mathrm{s}}^{\prime \prime t r}\right)$, and the upper branch, in a gal- lium-rich phase $\left(v_{\mathrm{s}}^{\mathrm{tr}}\right)$. When the temperature decreases further, the ultrasound velocity in the twophase field changes along the $v_{\mathrm{s}}^{\text {'tr }}$ and $v_{\mathrm{s}}^{\text {"tr }}$ curves down to the monotectic temperature. The $\mathrm{v}_{\mathrm{s}}^{\mathrm{tr}}$ and $\mathrm{v}_{\mathrm{s}}$ "tr curves limit the area of existence of two liquids in the $v_{\mathrm{s}}-T$ diagram. The temperature at which these curve merge is the critical temperature.

The deviation of our values of $v_{s}$ from the data in [7] obtained at a frequency of $5 \mathrm{MHz}$ does not exceed $0.6 \%$ over the entire temperature and concentration ranges. The exception is the melt with 40 at $\% \mathrm{~Pb}$, in which no anomalies in the $\mathrm{v}_{\mathrm{s}}(T)$ curve near $T_{\mathrm{mg}}$ was observed in [7]. 

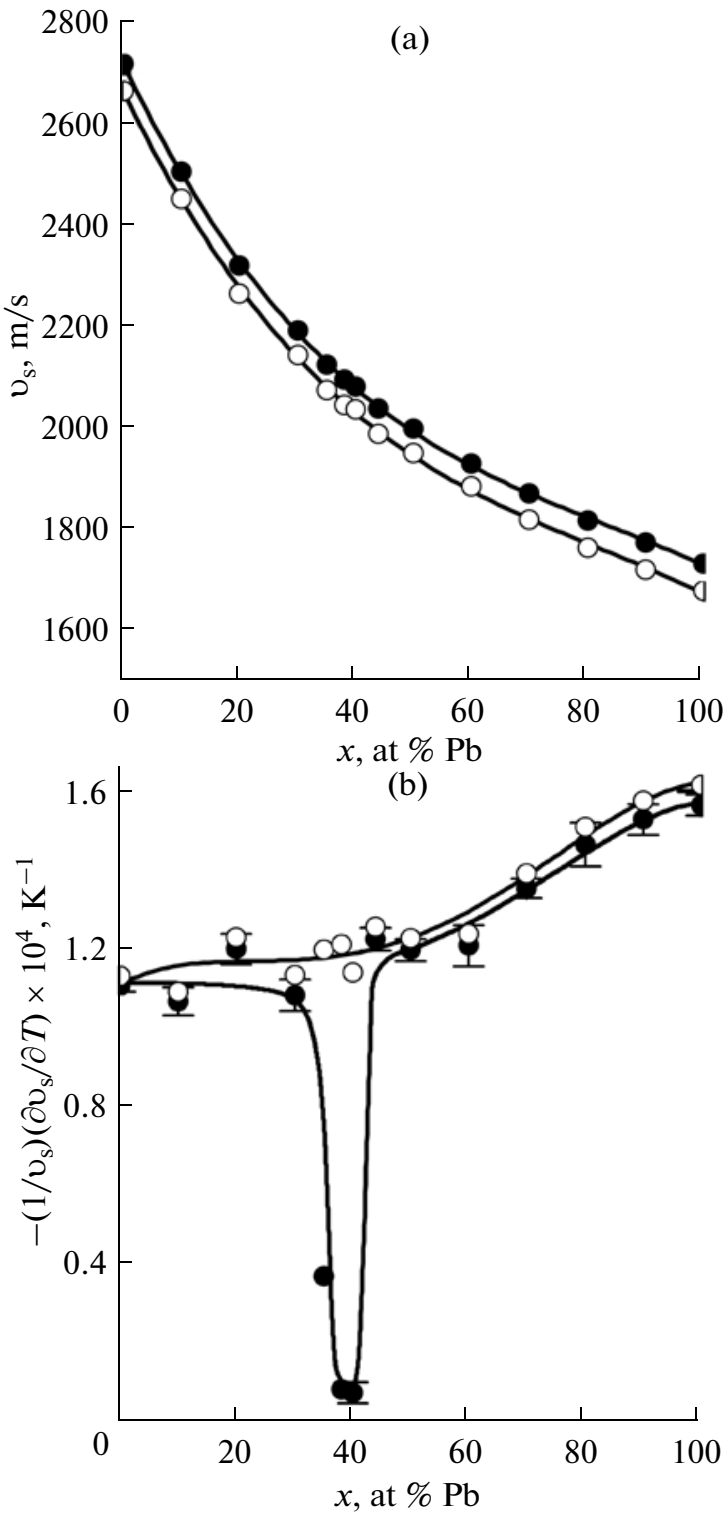

Fig. 3. (a) Concentration dependence of the ultrasound velocity and (b) its temperature coefficient for $\mathrm{Ga}-\mathrm{Pb}$ melts: (•) 900 and (O) $1100 \mathrm{~K}$.

Figure 3 shows the concentration dependences of ultrasound velocity $v_{\mathrm{s}}$ and its temperature coefficient for $\mathrm{Ga}-\mathrm{Pb}$ melts at 900 and $1100 \mathrm{~K}$. The ultrasound velocity isotherms do not exhibit specific features, and the concentration dependences of the temperature coefficient of $v_{\mathrm{s}}$ below $910 \mathrm{~K}$ has a deep minimum near 40 at $\% \mathrm{~Pb}$. This minimum is related to the anomaly of the temperature dependence of $v_{s}$ near the critical point (Fig. 2). The depth of the minimum grows when the critical temperature $T_{\mathrm{cr}}$ is approached.

The data on miscibility gap boundary $T_{\mathrm{mg}}(x)$ obtained in this work are presented in Fig. 4 and Tables 2 and 3 . The miscibility gap temperatures were measured by the two methods described above. Using these methods, we determined miscibility gap boundary $T_{\mathrm{mg}}(x)$, which is indicated by the solid line in Fig. 4. Figure 4 also shows the data from [7-13] and review [14]. The miscibility gap temperatures determined in this work agree well with the results in $[7,9-11,14]$ and are substantially lower than the data obtained in $[12,13]$ in the region with a high lead content. The results from [8] for gallium-rich melts are lower than the other data presented in Fig. 4.

Monotectic temperature $T_{\mathrm{m}}$ was determined by the static loading (SL) method and from the appearance of an acoustic signal after melting a sample. At a relatively low heating rate $(0.5-1 \mathrm{~K} / \mathrm{h})$, these methods give similar phase-transition temperatures. In the SL method, the heating rate weakly affects the measurement results, whereas the second method gives higher values of $T_{\mathrm{m}}$ at heating rates of $1 \mathrm{~K} / \mathrm{h}$ or higher. Therefore, the monotectic temperature in most samples of various compositions was determined by SL method.

Table 1. Coefficients in Eq. (4), error $\delta v_{s}$ in determining the ultrasound velocity, and the corresponding temperature ranges of measurement

\begin{tabular}{|c|c|c|c|c|}
\hline$x$, at $\% \mathrm{~Pb}$ & $b_{0}, \mathrm{~m} / \mathrm{s}$ & $b_{1}, \mathrm{~m} /(\mathrm{s} \mathrm{K})$ & $\delta v_{s}, m / s$ & $T, \mathrm{~K}$ \\
\hline 0 & $2934.7 \pm 5.2$ & $0.191 \pm 0.015$ & 1.6 & $303-380$ \\
\hline & $2973.7 \pm 2.2$ & $0.299 \pm 0.004$ & 3.4 & $380-1000$ \\
\hline 10 & $2746.3 \pm 7.4$ & $0.267 \pm 0.008$ & 2.1 & $787-1090$ \\
\hline 20 & $2571.5 \pm 7.7$ & $0.278 \pm 0.008$ & 1.4 & $862-1090$ \\
\hline 30 & $2405.9 \pm 8.0$ & $0.237 \pm 0.008$ & 1.5 & $879-1080$ \\
\hline 35 & $2348.8 \pm 6.5$ & $0.248 \pm 0.007$ & 1.3 & $900-1110$ \\
\hline 38 & $2317.8 \pm 5.3$ & $0.247 \pm 0.005$ & 1.3 & $907-1100$ \\
\hline 40 & $2295.3 \pm 4.9$ & $0.236 \pm 0.005$ & 0.9 & $910-1120$ \\
\hline 44 & $2262.7 \pm 3.8$ & $0.249 \pm 0.004$ & 1.4 & $885-1100$ \\
\hline 50 & $2213.7 \pm 5.1$ & $0.239 \pm 0.005$ & 1.0 & $876-1080$ \\
\hline 60 & $2142.0 \pm 9.1$ & $0.234 \pm 0.009$ & 1.6 & $872-1070$ \\
\hline 70 & $2097.8 \pm 4.0$ & $0.253 \pm 0.004$ & 0.9 & $852-1080$ \\
\hline 80 & $2056.6 \pm 8.1$ & $0.266 \pm 0.009$ & 1.3 & $808-1000$ \\
\hline 90 & $2017.9 \pm 5.7$ & $0.271 \pm 0.006$ & 1.6 & $707-1030$ \\
\hline 100 & $1976.7 \pm 2.9$ & $0.271 \pm 0.004$ & 1.2 & $601-920$ \\
\hline
\end{tabular}


Table 2. Phase compositions and the monotectic temperatures

\begin{tabular}{|c|c|c|c|c|c|}
\hline \multicolumn{3}{|c|}{ Phase composition, at $\% \mathrm{~Pb}$} & \multirow{2}{*}{$T, \mathrm{~K}$} & \multirow{2}{*}{ Investigation method } & \multirow{2}{*}{ Reference } \\
\hline $\mathrm{L}_{1}$ & $\mathrm{~L}_{2}$ & $(\mathrm{~Pb})$ & & & \\
\hline 1.8 & 94 & - & 586 & Ultrasound velocity & [7] \\
\hline- & - & - & 584.1 & Heat capacity & [8] \\
\hline 2.4 & 94.5 & - & 586 & DTA & [9] \\
\hline $2.4 \pm 0.1$ & $93.3 \pm 1.0$ & - & $586.0 \pm 1.5$ & $\gamma$ method & [10] \\
\hline- & - & - & $586.0 \pm 0.8$ & Electrical resistivity & [12] \\
\hline- & 86.47 & - & 590 & Thermal analysis & [15] \\
\hline- & 95.8 & 99.55 & $584 \pm 1$ & Melt quenching & [16] \\
\hline $2.4 \pm 0.1$ & $94.6 \pm 0.3$ & - & $586 \pm 1$ & Ultrasound velocity & This work \\
\hline
\end{tabular}

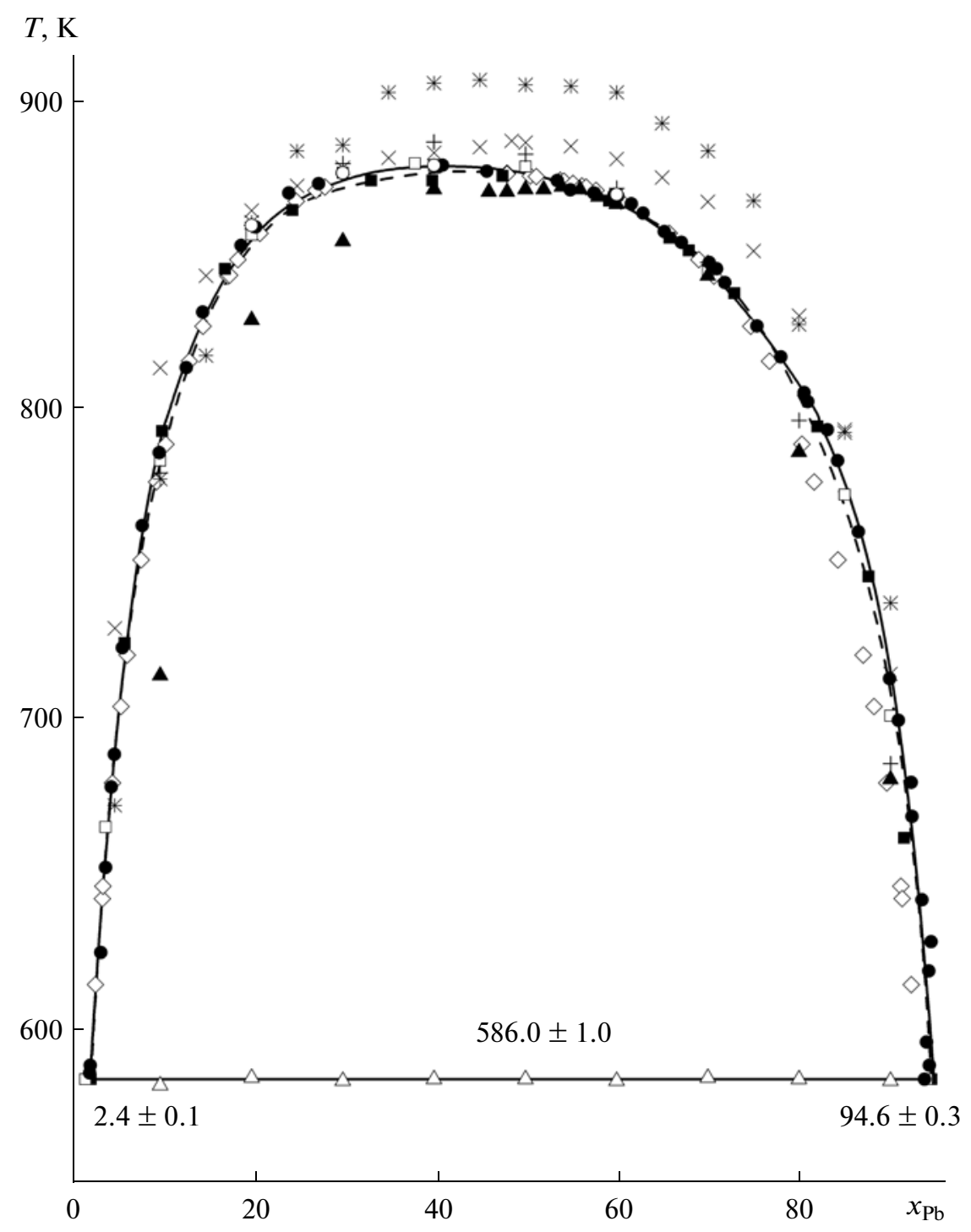

Fig. 4. Miscibility gap boundary in the $\mathrm{Ga}-\mathrm{Pb}$ phase diagram constructed $(\bigcirc)$ from ultrasonic signal amplitude, $(\bullet)$ from the ultrasound velocity, and $(\triangle)$ by the SL method in comparison with the reported data: $(\square)[7],(\Delta)[8],(\square)[9],(\diamond)[10],(+)[11]$, (*) [12], (X) [13], and (-- -) [14]. 


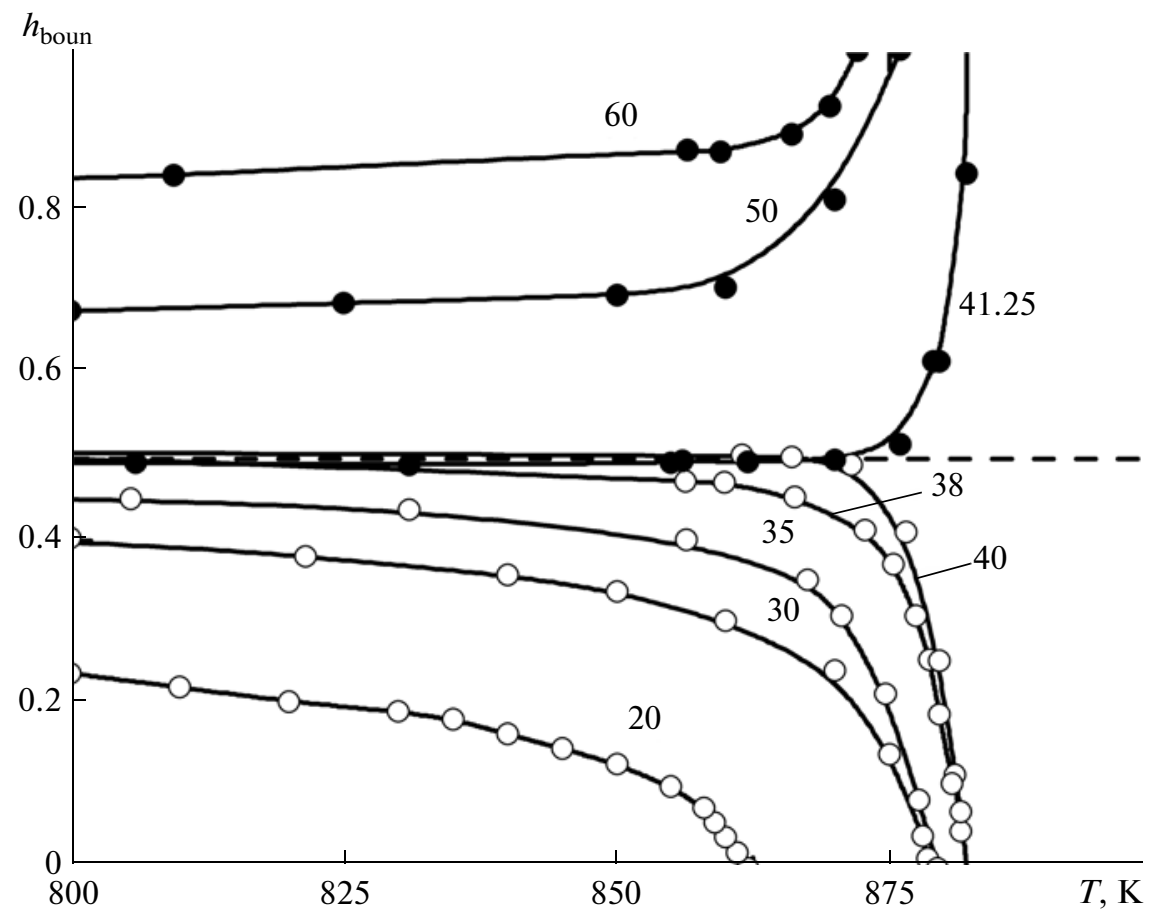

Fig. 5. Temperature dependences of the relative coordinate of the interphase boundary $h_{\text {boun }}$ in $\mathrm{Ga}-\mathrm{Pb}$ melts at $(\bigcirc) x<x_{\mathrm{cr}}$ and

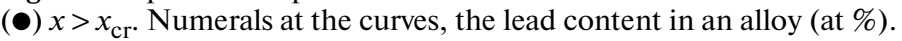

Figure 5 shows the temperature dependences of the coordinate of the boundary between liquid phases $h_{\text {boun }}$ for eight compositions. This boundary for the melts containing $20-40$ at $\% \mathrm{~Pb}$ lies in the lower half of the melt $\left(h_{\text {boun }}<0.5\right)$. As the temperature increases, it shifts downward and disappears near the crucible bottom at $T_{\mathrm{mg}}$. In contrast, in the melts with $41.25,50$, and 60 at $\% \mathrm{~Pb}$, the interphase boundary is located in the upper half of the melt and shifts toward the upper level of the melt ( $\left.h_{\text {boun }} \rightarrow 1\right)$ as the temperature increases.
To analyze these data, we express coordinate $h_{\text {boun }}$ as a function of temperature and composition,

$$
h_{\text {boun }}(x, T)=\frac{V^{\prime \prime} N^{\prime \prime}}{V^{\prime} N^{\prime}+V^{\prime \prime} N^{\prime \prime}}=\frac{V^{\prime \prime}\left(x-x^{\prime}\right)}{V^{\prime}\left(x^{\prime \prime}-x\right)+V^{\prime \prime}\left(x-x^{\prime}\right)},
$$

where $x^{\alpha}$ and $V^{\alpha}$ are the lead concentration and the molar volume of phase $\alpha$ (symbol $\alpha$ belongs to the gallium-rich (superscript ') or the lead-rich (superscript ") phase). The number of moles $N^{\prime}$ and $N^{\prime \prime}$ in the coexisting phases were determined from the lever rule. As follows from Eq. (5), condition $h_{\text {boun }}=0$ is always met

Table 3. Composition $\left(x_{\mathrm{cr}}\right)$ and temperature $\left(T_{\mathrm{cr}}\right)$ of the miscibility gap critical point

\begin{tabular}{|c|c|c|c|}
\hline$x_{\mathrm{cr}}$, at $\% \mathrm{~Pb}$ & $T_{\mathrm{cr}}, \mathrm{K}$ & Method of determining $x_{\mathrm{cr}}$ & Reference \\
\hline 37.9 & 882 & $\begin{array}{l}\text { From the maximum in a miscibil- } \\
\text { ity gap curve }\end{array}$ & [7] \\
\hline$\sim 50$ & 879 & The same & [9] \\
\hline $41.9 \pm 1.0$ & $879.3 \pm 1.5$ & Rectilinear diameter rule & [10] \\
\hline$\sim 40$ & 889 & $\begin{array}{l}\text { From the maximum in a miscibil- } \\
\text { ity gap curve }\end{array}$ & [11] \\
\hline $48.0 \pm 0.5$ & $909.0 \pm 1.6$ & Rectilinear diameter rule & [12] \\
\hline 48.5 & $889 \pm 1.3$ & The same & [13] \\
\hline $40.8 \pm 0.1$ & $881.6 \pm 1.0$ & $\begin{array}{l}\text { From the temperature depedence } \\
\text { of the vertical coordinate of the } \\
\text { interphase boundary }\end{array}$ & This work \\
\hline
\end{tabular}




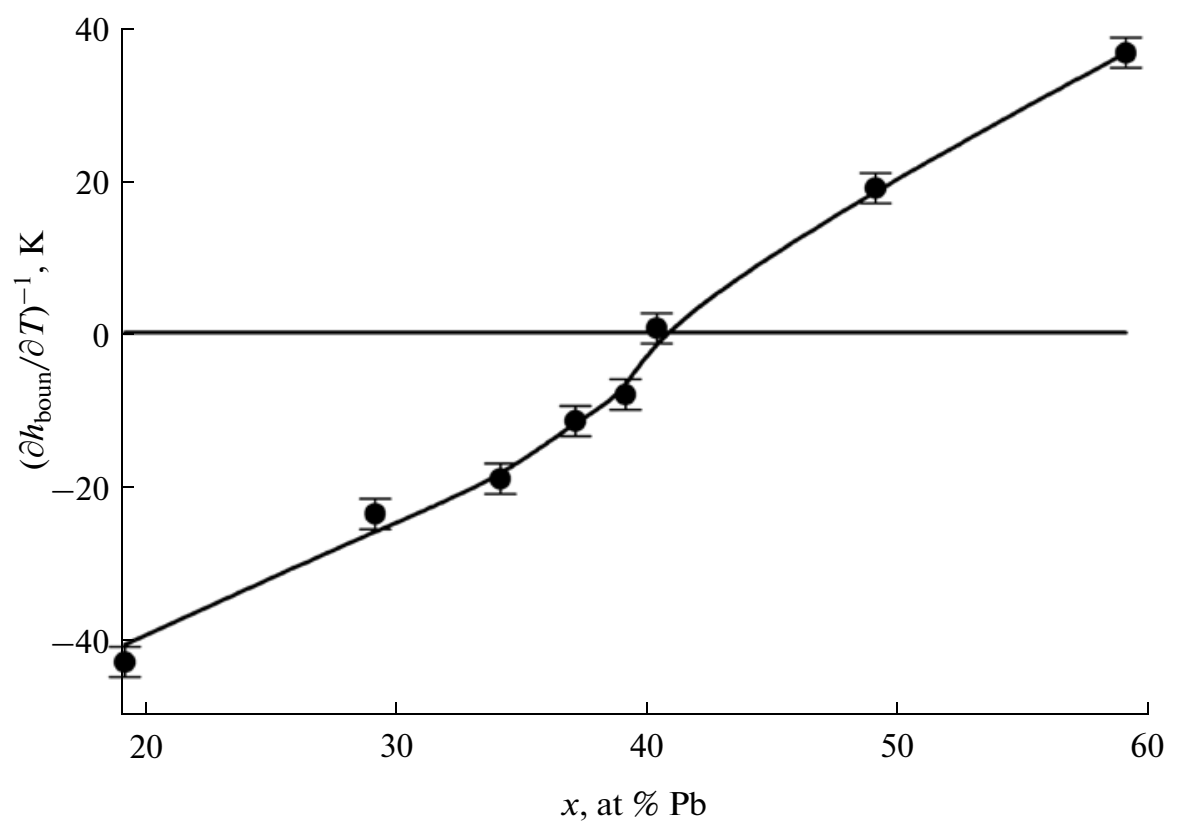

Fig. 6. Concentration dependence of the temperature derivative of interphase boundary coordinate $h_{\text {boun }}$ along the miscibility gap curve for $\mathrm{Ga}-\mathrm{Pb}$ melts.

for compositions $x<x_{\mathrm{cr}}$ along the miscibility gap curve $\left(x=x^{\prime}\right)$. In contrast, if $x>x_{\mathrm{cr}}$, we have $h_{\mathrm{boun}}=1$ along the miscibility gap curve $\left(x=x^{\prime \prime}\right)$.

To determine the critical composition accurately, we express the temperature derivative of $h_{\text {boun }}$ along the miscibility gap curve from Eq. (5),

$$
\begin{aligned}
& \left(\frac{\partial h_{\text {boun }}}{\partial T}\right)_{x=x^{\prime}}^{\prime}=-\frac{V^{\prime \prime}}{V^{\prime}} \frac{\left(\partial x^{\prime} / \partial T\right)}{x^{\prime \prime}-x^{\prime}}, \\
& \left(\frac{\partial h_{\text {boun }}}{\partial T}\right)_{x=x^{\prime \prime}}^{\prime \prime}=-\frac{V^{\prime}}{V^{\prime \prime}} \frac{\left(\partial x^{\prime \prime} / \partial T\right)}{x^{\prime \prime}-x^{\prime}} .
\end{aligned}
$$

It follows from these equations that the concentration dependences of $\left(\partial h_{\text {boun }} / \partial T\right)^{\prime}$ and $\left(\partial h_{\text {boun }} / \partial T\right)$ " become $-\infty$ and $+\infty$, respectively, at the critical point. In contrast to $\left(\partial h_{\text {boun }} / \partial T\right)$, the concentration dependence of $\left(\partial h_{\text {boun }} / \partial T\right)^{-1}$ is continuous and zero at the critical point. Therefore, this function can be used to determine the critical point. Figure 6 shows the concentration dependence of $\left(\partial h_{\text {boun }} / \partial T\right)^{-1}$ for a $\mathrm{Ga}-\mathrm{Pb}$ melt near the critical concentration. The critical concentration found from this dependence $\left(x_{\mathrm{cr}}=40.8 \pm 0.1\right.$ at $\left.\% \mathrm{~Pb}\right)$ coincides with the value $(41.9 \pm 1.0$ at $\% \mathrm{~Pb}$ [10]) obtained by the rectilinear diameter rule. Note that the accuracy of determining $x_{\mathrm{cr}}$ by this method is an order of magnitude higher than that of the rectilinear diameter rule.

Thus, the position of the miscibility gap determined in this work agrees well with the most reliable data obtained in other works. The proposed method of studying the temperature dependence of the vertical coordinate of the interphase boundary allowed us to determine $x_{\mathrm{cr}}$ more accurately as compared to the traditional rectilinear diameter rule.

\section{CONCLUSIONS}

Using a pulsed-phase method, we measured the temperature dependences of the ultrasound velocity in gallium, lead, and their alloys containing 10, 20, 30, $35,38,40,44,50,60,70,80$, and 90 at \% Ga. Anomalies were detected in the temperature dependences of the ultrasound velocity near the critical point. These anomalies are related to the preferred interaction of atoms of the same kind near the critical point and are most pronounced in the concentration dependence of the temperature coefficient of the ultrasound velocity. Below $910 \mathrm{~K}$ this dependence has a deep minimum near the critical composition. The depth of this minimum grows when the critical temperature is approached. The miscibility gap boundary determined by the acoustic method agrees well with the reported data.

\section{ACKNOWLEDGMENTS}

This work was supported by the Presidium of the Russian Academy of Sciences, project no. 12-P-31032.

\section{REFERENCES}

1. A. R. Skryshevskii, Structural Analysis of Liquids (Vysshaya Shkola, 1971).

2. P. P. Arsent'ev and L. A. Koledov, Metallic Melts and Their Properties (Metallurgiya, Moscow, 1976). 
3. V. V. Filippov, D. A. Yagodin, and P. S. Popel', "Acoustic method of measuring the interfacial tension at the boundary of immiscible liquids," Teplofizika Vysokikh Temperatur 47 (2), 201-206 (2009).

4. V. V. Filippov, "Acoustic investigations of the heterogeneous states of $\mathrm{Ga}-\mathrm{Pb}$ melts," Cand. Sci. (Phys.Math.) Dissertation, Yekaterinburg, Ural Polytechnical Institute, 2009.

5. V. G. Il'ves, V. V. Filippov, and S. P. Yatsenko, "Phase equilibria in the In-Bi-Pb system," Izv. Ross. Akad. Nauk, Ser. Met., No. 5, 166-168 (1992).

6. V. G. Il'ves, V. V. Filippov, and S. P. Yatsenko, " $\mathrm{In}_{2} \mathrm{Bi}-$ Ga phase diagram," Izv. Ross. Akad. Nauk, Ser. Met., No. 4, 231-235 (1993).

7. A. R. Regel', V. M. Glazov, and S. G. Kim, "Acoustic Studies of the structural changes in heating of semiconductor and semimetal melts," Fiz. Tekh. Poluprovodn. 20 (8), 1353-1375 (1986).

8. M. Mathon, J. M. Miane, P. Gaune, et al., "Gallium + lead system: molar heat capacity and miscibility gap," J. Alloys and Compounds 237, 155-164 (1996).

9. B. Predel, "Zustandsbilder gallium-blei und galliumthallium,” Z. Metallkd. 50 (4), 663-667 (1959).
10. R. A. Khairulin and S. V. Stankus, "Application of a $\gamma$ attenuation technique for the study of phase equilibria in binary liquid systems with a miscibility gap," High Temperatures-High Pressures 32 (2), 193-198 (2000).

11. A. Ben Abdellah, J. G. Gasser, A. Makradi, et al., "Resistivity of the liquid gallium-lead miscibility gap system,” Phys. Rev. B 68, 184201 (2003).

12. B. Sokolovskii, Yu. Plevachuk, and V. Didoukh, "Electroconductivity and liquid-liquid equilibrium in the $\mathrm{Pb}-\mathrm{Ga}$ system," Phys. Stat. Sol. (a) 148, 123-128 (1995).

13. Yu. O. Plevanchuk, V. M. Sklyarchuk, O. D. Alekhin, and L. A. Bulavin, "Viscosity of $\mathrm{Ga}-\mathrm{Pb}$ melts with a miscibility gap," Zh. Fizicheskikh Dostizhenii 9 (4), 333-335 (2005).

14. T. B. Massalski, Binary Alloy Phase Diagrams (Metals Park, Ohio, 1990).

15. N. A. Pushin, S. Stepanovic, and V. Stajic, "On the Gaalloys with $\mathrm{Zn}, \mathrm{Cd}, \mathrm{Hg}, \mathrm{Sn}, \mathrm{Pb}, \mathrm{Bi}$, and $\mathrm{Al}$," Z . Anorg. Chem 209, 329-334 (1932).

16. J. N. Greenwood, "The solid solutions of gallium in lead,” J. Inst. Met. 87, 91-93 (1958/59).

Translated by K. Shakhlevich 